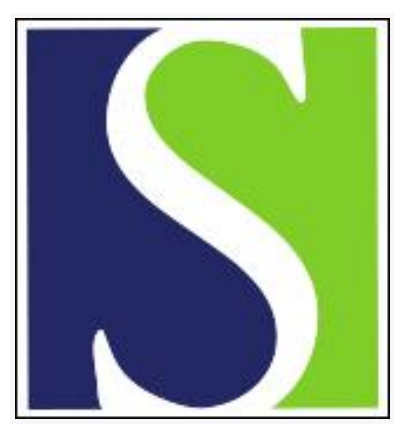

Scand J Work Environ Health 1984;10(2):83-87

https://doi.org/10.5271/sjweh.2354

Issue date: Apr 1984

Metabolism of inhaled ethylbenzene in rats.

by Engstrom KM

This article in PubMed: www.ncbi.nlm.nih.gov/pubmed/6474105

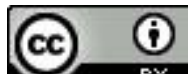

This work is licensed under a Creative Commons Attribution 4.0 International License 


\title{
Metabolism of inhaled ethylbenzene in rats
}

\author{
by Kerstin M Engström, PhL ${ }^{1}$
}

\begin{abstract}
ENGSTRÖM KM. Metabolism of inhaled ethylbenzene in rats. Scand J Work Environ Health 10 (1984) 83-87. Male Wistar rats were exposed to ethylbenzene $(0,300$, or $600 \mathrm{ppm}$ for $6 \mathrm{~h})$, and the metabolic fate of the compound was elucidated on the basis of the biotransformation products found in the urine. Fourteen different compounds thought to originate from ethylbenzene were identified. The main metabolites were 1-phenylethanol, mandelic acid, and benzoic acid. The metabolic conversion proceeded mainly through oxidation of the side chain, whereas ring oxidation seemed to be of minor importance. At the exposure level of $600 \mathrm{ppm}$, only $6 \%$ of the amount absorbed was eliminated in the urine during exposure. During the period of $48 \mathrm{~h}$ from the onset of exposure, the total urinary elimination was $59 \%$. The corresponding values at $300 \mathrm{ppm}$ were 13 and $83 \%$.
\end{abstract}

Key terms: acidic metabolites, alcoholic metabolites, inhalation studies, mass balance, phenolic metabolites, urine.

The basic application of ethylbenzene is for the production of styrene. However, a large amount is also consumed in connection with the use of xylene, as approximately $15 \%$ of technical xylene is ethylbenzene (12). Occupational exposure to ethylbenzene during the production of styrene is unlikely, whereas the use of xylene can cause workers' exposure to ethylbenzene. The metabolism of xylene has been studied extensively (4), but no complete overview of the biotransformation of ethylbenzene is available. The first study on this topic, published in 1923, reported that mandelic acid is formed from ethylbenzene in vivo (15). This conversion has later been demonstrated to occur in rats via 1-phenylethanol and acetophenone $(6,14)$. 1-Phenylethanol, mandelic acid, and phenylglyoxylic acid have been found in the urine of humans exposed to ethylbenzene (2).

The present study was done to obtain pertinent information on the metabolic fate of ethylbenzene in rats. Urine was chosen as the object of investigation mainly because the low concentrations of metabolites in the blood make their identification and measurement too difficult. The aim of the study was to identify the chemical structure of the metabolites excreted in the urine and to obtain quantitative data on the total mass balance; this objective can be achieved with thorough assays of the metabolite profile. Thus also intermediates and minor metabolites were sought. Their measurement may also be of interest from a toxicologic point of view.

\footnotetext{
1 Turku Regional Institute of Occupational Health, Turku,
} Finland.

Reprint requests to: Ms KM Engström, Turku Regional Institute of Occupational Health, Hämeenkatu 10, SF-20500 Turku, Finland.

\section{Material and methods}

\section{Experimental design}

Eighteen male Wistar rats $(310-395 \mathrm{~g})$ in groups of six animals each were exposed in identical dynamic exposure chambers $\left(1 \mathrm{~m}^{3}\right)$ to 0,300 , or $600 \mathrm{ppm}$ of ethylbenzene ( $99 \%$ pure, Fluka Ag, Switzerland) for $6 \mathrm{~h}$. The concentration was reached in the chamber air by the automatic feeding of air saturated with ethylbenzene into a stream of fresh air, which was then pumped into the chamber. A feedback control system maintained the desired concentrations. The concentration in each chamber was continuously recorded with an infrared Miran 1 A spectrophotometer (Wilks Scientific Corp, South Norwalk, the United States). The chamber air was exchanged at the rate of $5 \mathrm{~m}^{3} / \mathrm{h}$.

Because rats are nocturnal animals, they were adapted to an inverted 12-h daylight rhythm so that their exposure took place during the workday. Food but not drinking water was withheld during exposure. As the six rats of each group were housed together in two metabolic cages, the pooled urine gave the result for the respective group. The urine was collected $0-6,7-24,25-30$, and $31-48 \mathrm{~h}$ after the exposure began. All samples were immediately frozen and kept at $-18^{\circ} \mathrm{C}$ until analysis.

\section{Analytical methods}

Mandelic and benzoic acids (obtained by the alkaline hydrolysis of hippuric acid) were extracted from the urine by diethylether, silylated, and analyzed by gas chromatography $(8,9)$. Modifications of the methods were applied for the determination of phenylglyoxylic and phenylacetic acids (obtained by the alkaline hydrolysis of phenaceturic acid). These modifications are described in detail in another paper (7), which 
also reports the methods used to analyze the other compounds monitored in the urine. The principle of the latter-mentioned methods is as follows: the monitored compounds are liberated by enzymatic hydrolysis, extracted from the urine by diethylether or dichloromethane, and analyzed by capillary chromatography. The identity of the compounds was always verified by combined gas chromatography-mass spectrometry (LKB-9000); thus the mass spectral data of unknown peaks were compared with those of reference compounds. The specificity of the chromatographic peaks was checked simultaneously. For those compounds which are also normal urinary constituents, the values obtained for the exposed groups were corrected for the base excretion rates of the control group.

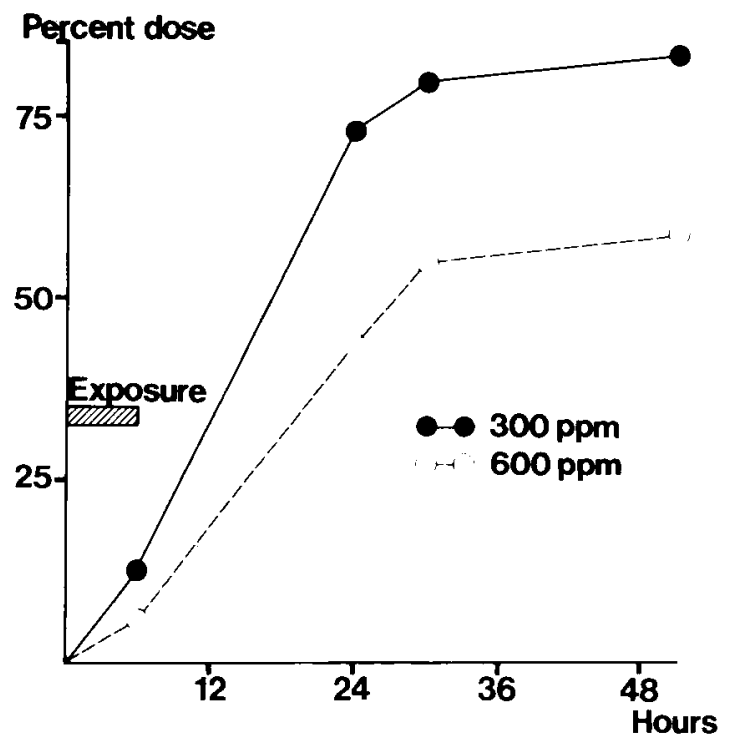

Figure 1. Cumulative excretion of ethylbenzene metabolites in the urine. The percentage of the dose was calculated on a molar basis.
Urinary thioethers were assayed according to the method of van Doorn et al (5) as described by Heinonen et al (10). The molar amounts of -SH-groups liberated by alkaline hydrolysis were detected with the Ellman reaction, ie, the dithiobisnitrobenzoic acid reaction. Known amounts of $N$-acetyl- $S$-benzyl cysteine, used as the standard, were added to water and processed in a manner identical to the procedure used for urine samples.

\section{Results}

In the estimation of the absorbed dose, the uptake of ethylbenzene was assumed to occur at a constant and continuous rate over the entire 6-h exposure period. It was also assumed that the absorbed proportion of the inhaled ethylbenzene at both exposure levels was $60 \%$, a figure derived from studies on humans ( 2 ; Riihimäki et al, unpublished results). This fraction, combined with the average minute volume of 0.127 l (tidal volume of $1.5 \mathrm{ml}$ times a respiration rate of 85 breaths $/ \mathrm{min}$ ) and the concentration of ethylbenzene in the inspired air, ie, $300 \mathrm{ppm}(12.3 \mu \mathrm{mol} / \mathrm{l})$ or 600 ppm $(24.6 \mu \mathrm{mol} / 1)$, resulted in a total absorbed dose of about $900 \mu \mathrm{mol} / \mathrm{kg}$ or $1,800 \mu \mathrm{mol} / \mathrm{kg}$, respectively. When the exposure level was $300 \mathrm{ppm}$, the metabolites of ethylbenzene excreted in the urine within $48 \mathrm{~h}$ after the onset of exposure amounted to $83 \%$, with $13 \%$ eliminated already during the 6 -h exposure period. The main part, $60 \%$, was found in the first postexposure sample $(7-24 \mathrm{~h}$ ) (figure 1 ). The higher exposure level $(600 \mathrm{ppm})$ did not, however, result in a corresponding increased excretion of metabolites. Only $6 \%$ of the absorbed dose was excreted in the urine during exposure. During the entire 48-h period that urine was collected, the urinary excretion was $59 \%$ (figure 1). For these mass balance estimations, the values of the exposed groups were corrected for the control group's base excretion of benzoic and phenylacetic acids.

Table 1. Elimination rates of the main metabolites of ethylbenzene in the urine during and after exposure.

\begin{tabular}{|c|c|c|c|c|}
\hline \multirow[b]{2}{*}{ Metabolite } & \multirow{2}{*}{$\begin{array}{c}\text { Exposure } \\
\text { level } \\
\text { (ppm) }\end{array}$} & \multicolumn{3}{|c|}{ Excretion rate $\left(\mu \mathrm{mol} \cdot \mathrm{h}^{-1} \cdot \mathrm{kg}^{-1}\right)$} \\
\hline & & $\begin{array}{c}0-6 \mathrm{~h} \\
\text { during exposure }\end{array}$ & $\begin{array}{c}0-18 \mathrm{~h} \\
\text { after exposure }\end{array}$ & $\begin{array}{c}19-42 \mathrm{~h} \\
\text { after exposure }\end{array}$ \\
\hline 1-Phenylethanol & $\begin{array}{l}300 \\
600\end{array}$ & $\begin{array}{l}10.7 \\
11.3\end{array}$ & $\begin{array}{l}6.3 \\
9.4\end{array}$ & $\begin{array}{l}0.3 \\
0.9\end{array}$ \\
\hline Mandelic acid & $\begin{array}{l}300 \\
600\end{array}$ & $\begin{array}{l}0.9 \\
0.8\end{array}$ & $\begin{array}{l}7.1 \\
9.8\end{array}$ & $\begin{array}{l}1.7 \\
5.4\end{array}$ \\
\hline Phenylglyoxylic acid & $\begin{array}{l}300 \\
600\end{array}$ & $\begin{array}{l}0.22 \\
0.45\end{array}$ & $\begin{array}{l}3.1 \\
3.8\end{array}$ & $\begin{array}{l}0.7 \\
2.1\end{array}$ \\
\hline Phenylacetic acid & $\begin{array}{l}\text { Control } \\
300 \\
600\end{array}$ & $\begin{array}{l}2.6 \\
7.6 \\
7.6\end{array}$ & $\begin{array}{l}2.6 \\
4.0 \\
4.2\end{array}$ & $\begin{array}{l}2.2 \\
2.1 \\
2.8\end{array}$ \\
\hline Benzoic acid & $\begin{array}{l}\text { Control } \\
300 \\
600\end{array}$ & $\begin{array}{l}21 \\
21 \\
20\end{array}$ & $\begin{array}{l}12 \\
23 \\
24\end{array}$ & $\begin{array}{l}14 \\
14 \\
14\end{array}$ \\
\hline
\end{tabular}


At both exposure levels the maximum rates of excretion were reached during the second collection period $(7-24 \mathrm{~h})$, when they were $30.8 \mu \mathrm{mol} \cdot \mathrm{h}^{-1}$ . $\mathrm{kg}^{-1}$ for exposure to $300 \mathrm{ppm}$ and $38.5 \mu \mathrm{mol} \cdot \mathrm{h}^{-1}$ . $\mathrm{kg}^{-1}$ for exposure to $600 \mathrm{ppm}$. During the first collection period the elimination rates for the two exposure levels were almost identical $(19.5 \mu \mathrm{mol}$ - $\mathrm{h}^{-1} \cdot \mathrm{kg}^{-1}$ for exposure to $600 \mathrm{ppm}$ and $19.2 \mu \mathrm{mol}$ - $\mathrm{h}^{-1} \cdot \mathrm{kg}^{-1}$ for exposure to $300 \mathrm{ppm}$ ) even though the lower exposure level was half the higher one. But the excretion rate the next day, 25 to $48 \mathrm{~h}$ after the exposure began, increased threefold, whereas the difference in the concentration in the inspired air was only twofold. According to table 1, where the excretion rates of the five main metabolites are presented, only 1-phenylethanol and phenylacetic acid have their peak excretions during exposure. The other acids (mandelic, phenylglyoxylic, and benzoic acids) were excreted at their maximum rates during the first $18 \mathrm{~h}$ after exposure.

None of the metabolites found was especially dominant (table 2). It can further be noted that the urinary metabolic pattern was very similar irrespective of the exposure level. Besides the compounds presented in table 2, traces of 2-ethylphenol, 2-phenylethanol, and m-hydroxyacetophenone were detected, but the amounts were too small for quantification. The formation of 4-ethylphenol from ethylbenzene could not be assessed with certainty, as the amounts excreted $\left(10.5 \mu \mathrm{mol} \cdot 48 \mathrm{~h}^{-1} \cdot \mathrm{kg}^{-1}\right.$ at $300 \mathrm{ppm}$ and $9.6 \mu \mathrm{mol}$ . $48 \mathrm{~h}^{-1} \cdot \mathrm{kg}^{-1}$ at $600 \mathrm{ppm}$ ) did not differ enough from the base excretion $\left(9.2 \mu \mathrm{mol} \cdot 48 \mathrm{~h}^{-1} \cdot \mathrm{kg}^{-1}\right)$ of the control group. Neither 3-ethylphenol nor ohydroxyacetophenone was found at all.

The excretion of alkali hydrolyzable thiol compounds (ie, mercapturic acids and related compounds) in the urine was increased in the exposed groups when they were compared with the control group. The magnitude of the increase was about threefold, but it remained at the same level in both exposed groups. The fraction excreted as thioethers accounted for about $2 \%$ of the total amount of metabolites excreted.

\section{Discussion}

Although the findings of the present study are based on only one pooled urine sample for each period of time and each level of exposure, satisfactory reliability can be expected. This assumption is based on the variability obtained in another study on the excretion of six individual rats after exposure to ethylbenzene (Engström et al, unpublished results). The standard deviations of the total amount of metabolites excreted were $10 \%$ after exposure to $300 \mathrm{ppm}$ and $16 \%$ after exposure to $600 \mathrm{ppm}$. The standard deviation of the percentage composition varied from 5 to $18 \%$ for the various metabolites. In the present study the conclusion about the origin of the compounds was based
Table 2. Percentage composition of the urinary metabolite pattern of ethylbenzene at two exposure levels.

\begin{tabular}{lcc}
\hline \multirow{2}{*}{ Metabolite } & \multicolumn{2}{c}{ Exposure level } \\
\cline { 2 - 3 } & $300 \mathrm{ppm}$ & $600 \mathrm{ppm}$ \\
\hline 1-Phenylethano! & 24.6 & 23.0 \\
Mandelic acid & 23.2 & 27.7 \\
Phenylglyoxylic acid & 9.9 & 10.9 \\
Phenylacetic acid & 7.3 & 6.6 \\
Benzoic acid & 27.0 & 23.9 \\
w-Hydroxyacetophenone & 4.7 & 4.6 \\
1-Phenyl-1,2-ethanediol & 1.1 & 0.9 \\
Acetophenone & 0.2 & 0.1 \\
p-Hydroxyacetophenone & 0.5 & 0.7 \\
Phenylglyoxal & 1.4 & 1.2 \\
\hline
\end{tabular}

on careful comparison between the urine of the control and the exposed groups. On the basis of the mass balance estimations, it seems justified to assume that all the metabolic products formed from ethylbenzene were identified even though no labeled precursors were available. The urinary elimination for the lower exposure level agrees, furthermore, with the observations of Chin et al (3) in a similar study with ${ }^{14} \mathrm{C}$ labeled ethylbenzene. He reported that the total uri. nary excretion of inhaled ethylbenzene $(230 \mathrm{ppm}, 6 \mathrm{~h})$ within $48 \mathrm{~h}$ was $82.6 \%$. The much lower recovery noted for the higher exposure level in the present study implies that saturation may have occurred. Kinetic studies on rats after the inhalation of styrene have demonstrated that metabolic clearance is saturated between 200 and $600 \mathrm{ppm}$ (13). If this model applies to ethylbenzene as well, then the metabolic clearance would be rate limiting in this study also.

The metabolism of ethylbenzene in rats was reconstructed on the basis of the compounds found in the urine (figure 2). The initial conversion of the chief metabolic pathway appears to be oxidation of the $\alpha$ carbon atom of the side chain, as has been suggested for rabbits (6). In that same study an alternative pathway (the oxidation of the $\omega$-methyl group of the side chain resulting in phenaceturic acid) was also detected. These results could be repeated in the present study. The latter pathway, moreover, was proved by the identification of an intermediate, 2-phenylethanol, in the urine. Bakke \& Scheline (1) reported that 0.2 to $0.4 \%$ of orally administered ethylbenzene was excreted in the form of 4-ethylphenol, the detection of which implies the occurrence of direct ring oxidation. However, due to interference from the base excretion, the extent of this third pathway could not be elucidated from the present data. According to Bakke \& Scheline the amount of 4-ethylphenol formed under conditions of the present study would be about 3 $\mu \mathrm{mol} \cdot 48 \mathrm{~h}^{-1} \cdot \mathrm{kg}^{-1}$, which, in view of both physiological and analytical variation, is too little for accurate measurement.

The first step of the chief metabolic pathway leads to 1-phenylethanol, which is both conjugated to glucuronide and excreted per se and converted, a process that results in many intermediates and end products. 


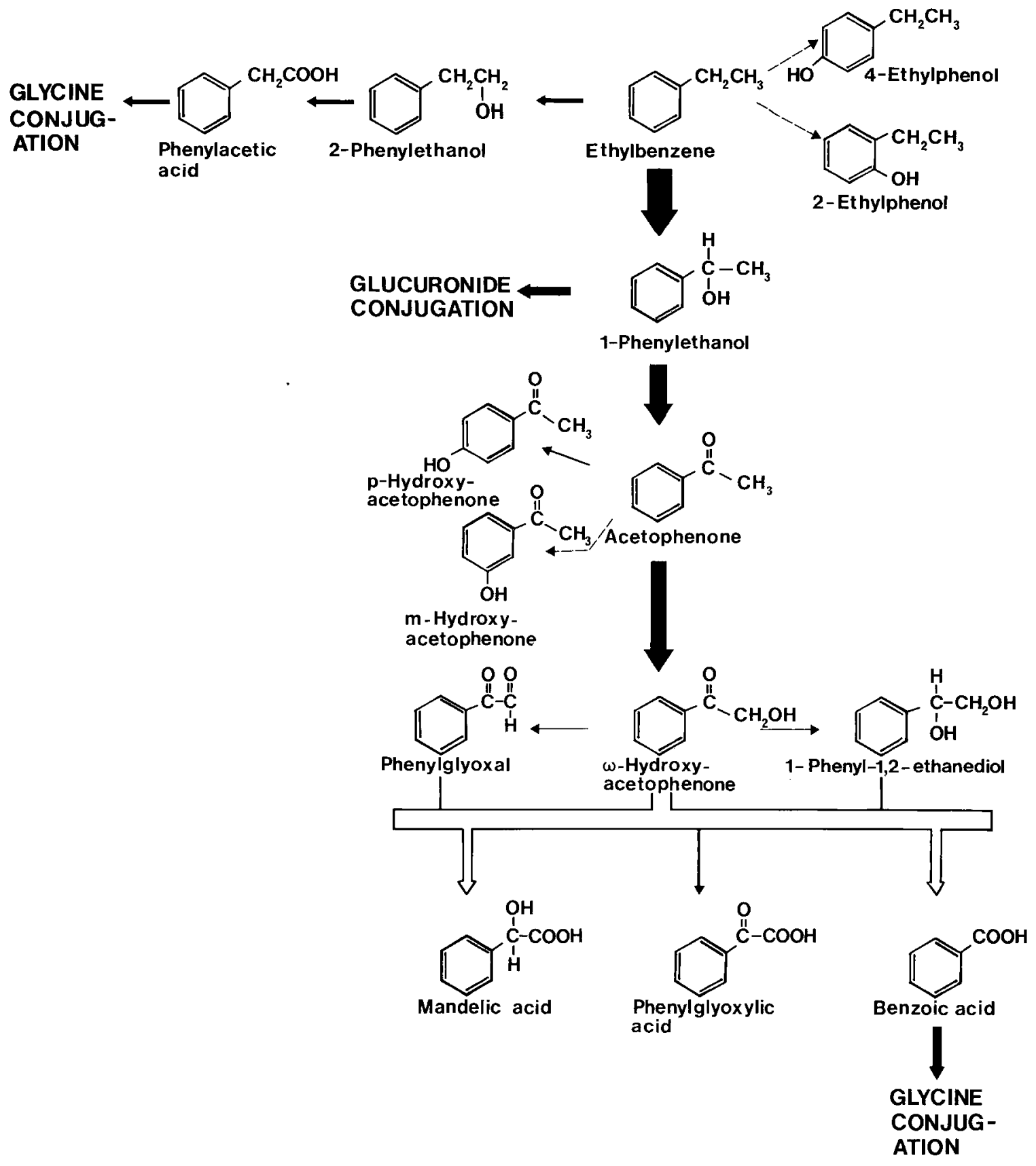

Figure 2. Metabolism of ethylbenzene as reconstructed from urinary metabolites found in the urine. The thickness of the arrows directly represents the extent of the respective route; the broken arrows mean that only trace amounts were found. Unclear pathways are depicted by open arrows.

The dehydrogenation of 1-phenylethanol gives acetophenone, which, to a small extent, is excreted in the urine. Most of the acetophenone is oxidized further in the ring or chain, and thereby $\mathrm{m}-$, $\mathrm{p}-$, and $\omega-$ hydroxyacetophenone is produced. The side chain of $\omega$-hydroxyacetophenone may be oxidized as well as reduced, with the result of either a diol (1-phenyl-1,2-ethanediol) or an $\alpha$-oxoaldehyde (phenylglyoxal). The role of these last-mentioned compounds as intermediates in the formation of mandelic and phenylglyoxylic acids is unclear. Sullivan et al (14) has shown that the administration of both phenylglyoxal and 1-phenyl-1,2-ethanediol results in the formation of about the same relative amount of mandelic and phenylglyoxylic acids as when ethylbenzene is the precursor. The ratio of 1-phenyl-1,2-ethanediol to phenylglyoxal measured in the present study does not reveal how $\omega$-hydroxyacetophenone is converted to mandelic and phenylglyoxylic acids. Nor is the process for the formation of benzoic acid known. It 
may be formed via mandelic acid or 1-phenyl-1,2ethanediol, as has been suggested for styrene $(11,16)$. The delayed excretion of mandelic and phenylglyoxylic acids seen at the higher exposure level but not at the lower one was, however, not found for benzoic acid (table 1). This phenomenon suggests that the carbon moiety may be split at an earlier stage, and thus neither mandelic acid nor phenylglyoxylic acid is an intermediate of benzoic acid. The form in which the alcoholic and phenolic metabolites are excreted is yet unknown, but both glucuronide conjugation and sulfate conjugation are thought to occur. The insignificant increase in the excretion of thioether among the exposed groups in the present study implies that gluthathione conjugation plays a minor role.

It is unclear how applicable the metabolic model presented in this paper is to man. Such information is, however, a prerequisite if metabolites are to be measured in exposure tests. Studies on human volunteers are therefore continuing, and the results of that research will be presented in the near future.

\section{Acknowledgments}

The author is greatly indebted to Ms E Korolainen and Ms S Lauren for their skillful technical assistance, and Ms E Elovaara for her expert help in carrying out the exposures. The linguistic revision by S Hinkkanen, MA, is gratefully acknowledged.

\section{References}

1. Bakke OM, Scheline RR. Hydroxylation of aromatic hydrocarbons. Toxicol Appl Pharmacol 16 (1970) $691-700$.

2. Bardodej Z, Bardodejova E. Biotransformation of ethylbenzene, styrene and alpha-methylstyrene in man. Am Ind Hyg Assoc J 31 (1970) 206-209.

3. Chin BH, Kelvey JA, Tyler TR, Calisti LJ, Kozbelt SJ, Sullivan LJ. Absorption, distribution and excretion of ethylbenzene, ethylcyclohexane and methylethylbenzene isomers in rats. Bull Environ Contam Toxicol 24 (1980) $477-483$.
4. Dean BJ. Genetic toxicology of benzene, toluene, xylenes and phenols. Mutat Res 47 (1978) 75-97.

5. Doorn R van, Leijdekker C-M, Bos RP, Brouns RM, Henderson PT. Enhanced excretion of thioethers in urine of operators of chemical waste incinerators. Br J Ind Med 38 (1981) 187-190.

6. El Masry AM, Smith JN, Williams RT. The metabolism of alkylbenzenes: n-Propylbenzene and butylbenzene with further observation on ethylbenzene. Biochem $\mathbf{J}$ 64 (1956) 50-56.

7. Engström K. Urinalysis of minor metabolites of ethylbenzene and m-xylene. Scand J Work Environ Health 10 (1984) 75-81.

8. Engström K, Husman K, Rantanen J. Measurement of toluene and xylene metabolites by gas chromatography. Int Arch Occup Environ Health 36 (1976) 153-160.

9. Engström K, Rantanen J. A new gas chromatographic method for determination of mandelic acid in urine. Int Arch Occup Environ Health 33 (1974) 163-167.

10. Heinonen $T$, Kytöniemi V, Sorsa M, Vainio $H$. Urinary excretion of thioethers among low-tar and medium-tar cigarette smokers. Int Arch Occup Environ Health 52 (1983) $11-16$.

11. Leibman KC. Metabolism and toxicity of styrene. Environ Health Perspect 11 (1975) 115-119.

12. National Institute for Occupational Safety and Health. Criteria for a recommended standard: Occupational exposure to xylene. US Department of Health Education and Welfare, US Government Printing Office, Washington, DC 1975, p 14.

13. Ramsey JC, Young JD. Pharmacokinetics of inhaled styrene in rats and humans. Scand J Work Environ Health 4 (1978): suppl 2, 84-91.

14. Sullivan HR, Miller WM, McMahon RE. Reaction pathways of in vivo stereoselective conversion of ethylbenzene to $(+)-$ mandelic acid. Xenobiotica $6(1976)$ $49-54$.

15. Thierfelder H, Daiber K. Zur Kenntniss des Verhaltens fettaromatischer ketone im Tierkörper. Hoppe Seyler's Z physiol Chem 130 (1923) 380-396.

16. Vainio $H$, Tursi F, Belvedere $G$. What are the significant toxic metabolites of styrene? In: Hietanen E, Laitinen $M$, Hänninen $O$, ed. Cytochrome $P 450$, biochemistry, biophysics and environmental implications. Elsevier Biomedical Press, Amsterdam 1982, pp $679-687$.

Received for publication: 10 August 1983 